\section{Effects of unilateral lateral rectus recession according to the tendon width in intermittent exotropia}

\begin{abstract}
Purpose To verify the effect of unilateral lateral rectus recession for each millimeter according to the tendon width in intermittent exotropia. Methods A total of 37 patients (37 eyes) of 7 to 11 years of age with basic-type intermittent exotropia and a deviation of 16-25 Prism Diopters (PD) were included in this study. Under general anaesthesia, the tendon width of the lateral rectus of the deviating eye near insertion was measured with calipers, prior to dissection of the muscle tendon from the sclera. Patients underwent $6.5-10 \mathrm{~mm}$ unilateral lateral rectus recession. The effect of lateral recession for each millimeter was the absolute value of the angle of preoperative deviation plus postoperative deviation on the second day divided by the total amount of recession. Results Mean tendon width of the lateral rectus of a deviating eye was $8.3 \mathrm{~mm}$ (range: 6.5-9.5). The mean effect per millimeter of unilateral rectus recession in those 37 patient was $2.98 \pm 0.42$ PD (range: $2.4-4.1$ ). The effect of recession was larger in cases in which the tendon width of the lateral rectus was narrower $(P=0.000, r=0.72)$.

Conclusion The tendon width of the lateral rectus muscle can be a useful indicator to estimate the effect of lateral rectus recession in intermittent exotropia.
\end{abstract}

Eye (2006) 20, 785-788. doi:10.1038/sj.eye.6702002; published online 8 July 2005

Keywords: unilateral lateral rectus recession; tendon width; intermittent exotropia

\section{Introduction}

Overcorrection of exotropia in the early postoperative period gives the best long-term

S-H Kim, Y-J Choi

results for intermittent exotropia. ${ }^{1}$ Scott $e t a l^{2}$ suggested the range of 4-16 Prism Diopter (PD) esodeviation, and Raab and Parks ${ }^{1}$ reported that initial (2-10 days) postoperative alignment between 11 and 20 PD esodeviation remained satisfactory. They also suggested a table of lateral rectus recession for producing the above results. Although this surgical dosage table should serve only as a guide and be modified according to each individual patient and surgical technique, it has become the general scheme of the surgeon. According to their table, the effect of lateral rectus recession for each millimeter is about 3 PD. It has been conceived that the effect of lateral rectus recession increases as the tendon and muscle proper width of lateral rectus decreases, but we were unaware that this concern had been mentioned in the abundant literature dealing with surgical procedures for intermittent exotropia. The aim of this study was to document the effect of unilateral lateral rectus recession for each millimeter according to the tendon width and to give information to surgeons for planning the amount of lateral rectus recession in intermittent exotropia.

Patients and methods

Included in this study were 37 patients (37 eyes) who had undergone recession of only the unilateral lateral rectus muscle as treatment for intermittent exotropia of the basic type. Patients who had undergone previous surgery, those who were younger than 6 years of age, those with myopia and hyperopia greater than 2 PD, anisometropia above $2 \mathrm{D}$, amblyopia with corrected vision worse than 20/25, and those with lateral incomitance of more than 5 PD were excluded.
Department of

Ophthalmology, Korea University College of

Medicine, Ansan, Korea

Correspondence: S-H Kim, Department of

Ophthalmology, Korea University Ansan Hospital 516, Gojan-dong, Gyunggi-do 425-707, South Korea

Tel: + 8231412 5160;

Fax: + 82314148930

E-mail: ansaneye@

hanmail.net

Received: 22 March 2005 Accepted in revised form: 27 May 2005

Published online: 8 July 2005 
Alternate prism cover testing was performed at a distance of $6 \mathrm{~m}$ with the patient in primary gaze, both right and left gaze, and up and down gaze. Alternate prism cover testing was then performed in primary position at $30 \mathrm{~cm}$. Under general anesthesia and prior to dissection of the muscle tendon from the sclera, the tendon width of the lateral rectus of the deviating eye near insertion was measured with calipers (Figure 1).

The angle of strabismus was then measured at both distant and near distances on the first and second day postsurgery, and then 1 month and 3 months postsurgery. We selected the angle of deviation at a distance of $6 \mathrm{~m}$ on the second day after surgery to estimate the effect of lateral rectus recession. The followup period of observation was relatively short, mainly because this study focused only on the immediate overcorrection and pure effect of lateral rectus recession. We calculated that the pure effect of lateral recession for each millimeter was the absolute value of the angle of preoperative deviation plus postoperative deviation on the second day divided by total amount of recession. All statistical analyses were performed using the Kluskal-Wallis test and linear regression analysis.

\section{Results}

The mean age of patients in this study was 8.9 years old (range: 7-11). Mean angle of strabismus in primary gaze was 19.9 \pm 3.17 PD (range: 16-25) and mean amount of recession was $8.5 \pm 1.17 \mathrm{~mm}$ (range: $6.5-10$ ). Mean tendon width of the lateral rectus of the deviating eye was $8.3 \pm 0.72 \mathrm{~mm}$ (range: $6.5-9.5$ ). Mean angles of strabismus were $5.3 \pm 3.22 \mathrm{PD}$ esodeviation on the second postoperative day, $3.3 \pm 5.71 \mathrm{PD}$ exodeviation at one month and $4.5 \pm 4.22 \mathrm{PD}$ exophoria at 3 months after surgery. Consecutive esotropia and lateral incomitance did not occur in this follow-up period. The mean effects of unilateral rectus recession in those 37 patients were

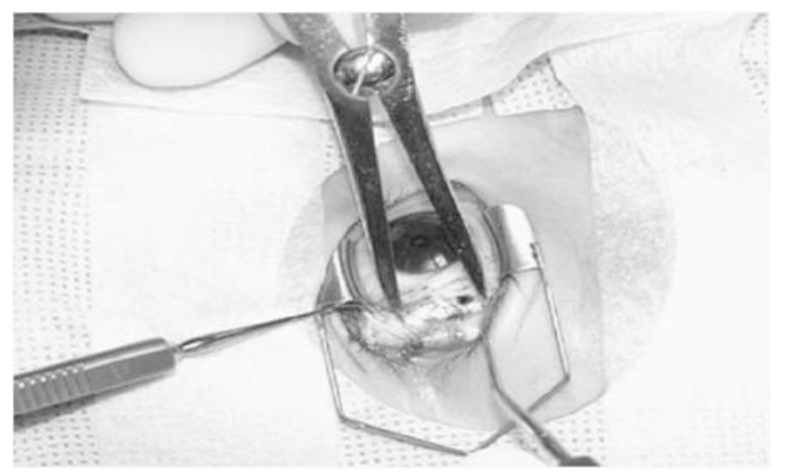

Figure 1 Photograph shows the tendon width of the lateral rectus near insertion as measured with calipers.
$25.2 \pm 5.13 \mathrm{PD}$ and the mean effect per millimeter was $2.98 \pm 0.42$ PD (range: $2.4-4.1$ )(Table 1). As predicted, the effects of recession were larger in cases in which the tendon width of the lateral rectus was decreased ( $P=0.000, r=0.72$ ) (Figure 2). When subdividing the effect of recession according to tendon width of the lateral rectus, the mean effect per millimeter was $3.5 \pm 0.40,2.9 \pm 0.24$, and $2.7 \pm 0.26 \mathrm{PD}$ when ranges of tendon width were $6.5-7.5 \mathrm{~mm}$ (nine patients), $8-8.5 \mathrm{~mm}$ (16 patients), and $9-9.5 \mathrm{~mm}$ (13 patients), respectively. These results were determined to be statistically significant $(P=0.000)$ by the Kluskal-Wallis test (Table 2$)$.

\section{Discussion}

Surgical treatment options for intermittent exotropia may include bilateral lateral rectus recession or unilateral lateral rectus recession combined with medial rectus resection (R\&R). ${ }^{3}$ Unilateral lateral rectus recession has been previously used for the treatment of moderate angle intermittent exotropia. However, the results reported have been inconsistent. ${ }^{4-6}$ For this study, we chose patients upon whom only unilateral lateral rectus recession had been performed because it was difficult to calculate the effects of bilateral lateral rectus recession if tendon widths could be different between both eyes. Moreover, it is more difficult to estimate the exact effects of unilateral $R \& R$ because the effects of medial $R \& R$ can differ considerably according to the technique used.

We selected the angle of strabismus on the second day after surgery in order to estimate the pure effect of lateral rectus recession. This is in accordance with previous studies. Specifically, the surgeon who recesses the lateral rectus muscles should anticipate \pm 20 PD esotropia in the primary position on the second or third postoperative day. ${ }^{1,7}$ This is significantly reduced by the tenth postoperative day and the immediate overcorrection usually disappears by the third postoperative week. ${ }^{3}$

Several factors influence the quantity of surgery and surgical outcomes to correct the intermittent exotropia. In order to solve this problem, we applied strict exclusion criteria. We excluded amblyopia, lateral incomitance, high AC/A ratio, and refractive error. ${ }^{8}$ However, Kushner ${ }^{9}$ reported that the influence of axial length and refractive error is clinically unimportant in regard to intermittent exotropia. We also selected patients who were older than 6 years. In a retrospective study of intermittent exotropia according to age group by Richard and Parks, ${ }^{10}$ most satisfactory results occurred in the group between the ages of 6 and 17 years. The above enumeration of exclusion criteria was designed to unify the preoperative conditions of the patients for the purpose of this study. 
Table 1 Profiles of the 37 patients

\begin{tabular}{|c|c|c|c|c|c|c|}
\hline Patient no & $\begin{array}{c}\text { Preoperative } \\
\text { deviation (PD) }\end{array}$ & $\begin{array}{c}\text { Recession } \\
\text { amount }(\mathrm{mm})\end{array}$ & $\begin{array}{l}\text { Tendon width } \\
(\mathrm{mm})\end{array}$ & $\begin{array}{c}\text { Postoperative } \\
\text { deviation }(P D)^{*}\end{array}$ & $\begin{array}{l}\text { Total effect of } \\
\text { recession (PD) }\end{array}$ & $\begin{array}{c}\text { Effect per each } \\
\text { recession }(P D / \mathrm{mm})\end{array}$ \\
\hline 1 & 16 & 7 & 8 & -4 & 20 & 2.85 \\
\hline 2 & 18 & 8.5 & 9.5 & -2 & 20 & 2.35 \\
\hline 3 & 25 & 10 & 8 & -8 & 33 & 3.30 \\
\hline 4 & 16 & 7 & 8 & -4 & 20 & 2.85 \\
\hline 5 & 25 & 10 & 7.5 & -12 & 37 & 3.70 \\
\hline 6 & 20 & 9 & 8.5 & -4 & 24 & 2.67 \\
\hline 7 & 25 & 10 & 8 & -4 & 29 & 2.90 \\
\hline 8 & 25 & 10 & 9 & -6 & 31 & 3.10 \\
\hline 9 & 20 & 9 & 9 & -2 & 22 & 2.44 \\
\hline 10 & 25 & 10 & 8.5 & -8 & 33 & 3.30 \\
\hline 11 & 16 & 7 & 7.5 & -4 & 20 & 2.85 \\
\hline 12 & 20 & 9 & 8.5 & -4 & 24 & 2.67 \\
\hline 13 & 20 & 9 & 9 & -4 & 24 & 2.67 \\
\hline 14 & 16 & 7 & 8.5 & -4 & 20 & 2.85 \\
\hline 15 & 18 & 7.5 & 9 & -2 & 20 & 2.70 \\
\hline 16 & 16 & 6.5 & 7.5 & -9 & 25 & 3.85 \\
\hline 17 & 18 & 7.5 & 9 & -2 & 20 & 2.67 \\
\hline 18 & 18 & 9.5 & 8 & -9 & 27 & 2.84 \\
\hline 19 & 20 & 9 & 9 & -4 & 24 & 2.67 \\
\hline 20 & 20 & 8 & 9 & -2 & 22 & 2.75 \\
\hline 21 & 25 & 10 & 9 & -8 & 33 & 3.30 \\
\hline 22 & 16 & 7 & 7 & -10 & 26 & 3.71 \\
\hline 23 & 20 & 8 & 9 & -2 & 22 & 2.75 \\
\hline 24 & 16 & 7 & 7 & -10 & 26 & 3.71 \\
\hline 25 & 20 & 9 & 8.5 & -6 & 26 & 2.89 \\
\hline 26 & 18 & 8.5 & 8 & -2 & 20 & 2.35 \\
\hline 27 & 25 & 10 & 7.5 & -6 & 31 & 3.10 \\
\hline 28 & 22 & 8 & 7 & -4 & 26 & 3.25 \\
\hline 29 & 25 & 10 & 6.5 & -16 & 41 & 4.10 \\
\hline 30 & 20 & 9 & 8 & -6 & 26 & 2.89 \\
\hline 31 & 16 & 7 & 9 & -5 & 21 & 3.00 \\
\hline 32 & 16 & 7 & 8 & -6 & 22 & 3.14 \\
\hline 33 & 22 & 8 & 8 & -4 & 26 & 3.25 \\
\hline 34 & 20 & 8 & 8 & -2 & 22 & 2.75 \\
\hline 35 & 20 & 7 & 8 & -2 & 22 & 3.14 \\
\hline 36 & 20 & 10 & 9 & -6 & 26 & 2.60 \\
\hline 37 & 20 & 9 & 9 & -2 & 22 & 2.44 \\
\hline Mean & 19.9 & 8.5 & 8.3 & -5.3 & 25.2 & 2.98 \\
\hline
\end{tabular}

*Minus values mean esodeviation.

We performed the $6.5-10 \mathrm{~mm}$ of unilateral lateral rectus recession. All patients did not reveal limitation of abduction postoperatively. A previous study has demonstrated that a $11-12 \mathrm{~mm}$ recession of the lateral rectus muscle results in the limitation of abduction, and lateral incomitance. ${ }^{11}$

Traditionally, it has been conceived that strabismic surgeons experienced surgical outcomes to achieve an average correction of $3 \mathrm{PD} / \mathrm{mm}$ in lateral rectus recession. ${ }^{12}$ These results corresponded with our results of $2.98 \mathrm{PD} / \mathrm{mm}$. However, appreciable differences of effects existed according to the tendon width of lateral recti, a result that is statistically significant. The tendon width is easy to measure preoperatively in the operating room; thus, it can be a useful indicator for predicting the result of lateral rectus recession.
A disturbance in the tonic horizontal vergence is usually considered the cause of most primary divergent deviation. Secondary anatomical factors probably occur within and around the extraocular muscles. Excess innervation to the lateral recti may possibly result in hypertrophy. ${ }^{3}$ According to the above theory, the thickness and width of the muscle proper is more important than the tendon width for predicting the effects of lateral rectus recession. However, the thickness and width of the muscle proper vary in their travelling courses. We think the tendon width of lateral recti might speak for the hypertrophy of the muscles, and our results showed that this theory could be correct.

In conclusion, the tendon width of the lateral rectus muscle can be a useful indicator for estimating the effect of lateral rectus recession in intermittent exotropia. The 


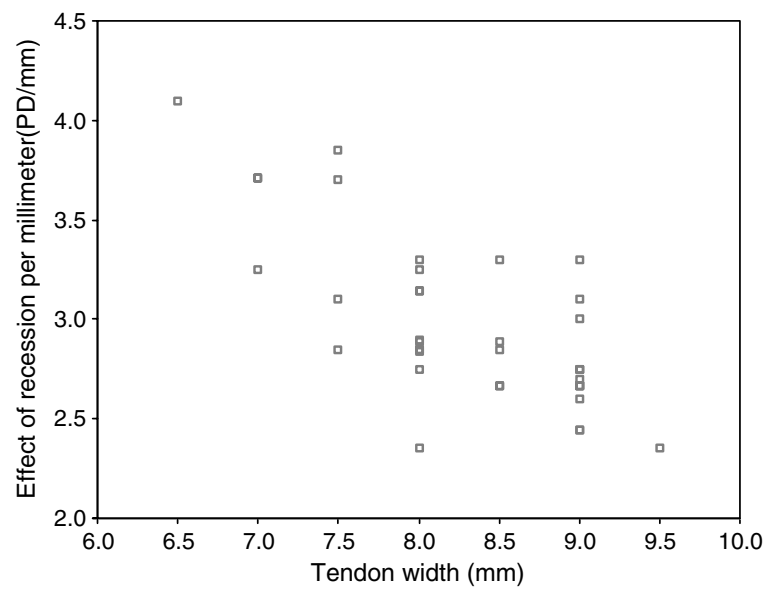

Figure 2 Graph depicting the relationship between tendon width and effect of lateral rectus recession per millimeter ( $P=0.000, r=0.72$ by linear regression analysis).

Table 2 Effect of recession according to tendon width of lateral rectus

\begin{tabular}{lcc}
\hline $\begin{array}{l}\text { Tendon width } \\
(\mathrm{mm})\end{array}$ & $\begin{array}{c}\text { Effect per each } \\
\text { recession }(P D / \mathrm{mm})\end{array}$ & No. of patients \\
\hline $6.5-7.5$ & $3.5 \pm 0.40$ & 8 \\
$8-8.5$ & $2.9 \pm 0.24$ & 16 \\
$9-9.5$ & $2.7 \pm 0.26$ & 13 \\
\hline
\end{tabular}

$P=0.000$ by Kluskal-Wallis test.

quantification of hypertrophy of the extraocular muscle will have to be further investigated in future studies.

\section{References}

1 Raab EL, Parks MM. Recession of the lateral recti: early and late postoperative alignment. Arch Ophthalmol 1969; 82: 203-208.

2 Scott WE, Keech R, Marsh AJ. The postoperative results and stability of exodeviation. Arch Ophthalmol 1981; 99: 1814-1818.

3 Jasman W, Jaeger EA. Concomitant exodeviation. In: Parks MM and Mitchell PR (eds) Duane's clinical ophthalmology. JB Lippincott company: Philadelphia, Vol 1, Chapter 131991.

4 Lee OS, O'Brien CS. Surgical treatment of concomitant divergent strabismus. In: Allen JH (ed) Strabismus Ophthalmic Symposium. CV Mosby: St Louis, 1950 p 396.

5 Urist MJ. Exotropia with bilateral elevation in adduction: surgery. Am J Ophthalmol 1954; 38: 178-190.

6 Deutsch JA, Nelson LB, Sheppard RW, Burke MJ. Unilateral lateral rectus recession for treatment of exotropia. Ann Ophthalmol 1992; 24: 111-113.

7 Hardesty HH, Boynton JR, Keenan JP. Treatment of intermittent exotropia. Arch Ophthalmol 1978; 96: 268-274.

8 Scott AB, Marsh J, Jampolsky A. Quantitative guidelines for exotropia surgery. Invest Ophthalmol 1975; 14(6): 428-436.

9 Kushner BJ, Fisher MR, Lucchese NJ, Morton GV. Factors influencing response to strabismus surgery. Arch Ophthalmol 1993; 111: 75-79.

10 Richard JM, Parks MM. Intermittent exotropia. Surgical results in different age groups. Ophthalmology 1983; 90: 1172-1177.

11 Urist MJ. Unilateral intermittent exotropia. Ann Ophthalmol 1976; 48: 260-267.

12 Dadeya S, Kamlesh. Long-term results of unilateral lateral rectus recession in intermittent exotropia. J Pediatr Ophthalmol Strabismus 2003; 40: 283-287. 